\title{
THOUGHT SUPPRESSION RESEARCH METHODS: PARADIGMS, THEORIES, METHODOLOGICAL CONCERNS
}

\begin{abstract}
It is hard to provide an unequivocal answer to the question of whether or not thought suppression is effective. Two thought suppression paradigms - the "white bear" paradigm and the think/no-think paradigm give mixed results. Generally, "white bear" experiments indicate that thought suppression is counterproductive, while experiments in the think/no-think paradigm suggest that it is possible to effectively suppress a thought. There are also alternative methods used to study thought suppression, for instance the directed forgetting paradigm or the Stroop task. In the article, I describe the research methods used to explore thought suppression efficacy. I focus on the "white bear" and the think/no-think paradigms and discuss theories proposed to explain the results obtained. I also consider the internal and external validity of the methods used.

Keywords: thought suppression, the "white bear" paradigm, the think/no-think paradigm, external validity, internal validity.
\end{abstract}

\section{Introduction}

Thought suppression is the volitional activity of the mind aimed at stopping a particular mental content from entering consciousness. There are many methods of studying this phenomenon. Interestingly, however, the conclusions of the research often depend on the type of method used (Levy \& Anderson, 2008; Rassin, 2005). This is unfortunate, especially given the importance of the issue. Approximately $80 \%$ of mentally healthy people regularly experience unwanted thoughts (Rachman \& de Silva, 1978). They may wish to get rid of disturbing or unpleasant thoughts, such as those having to do with difficult life situations, temptations, experienced pain, stereotypes, etc. (Wenzlaff \& Wegner, 2000). And, perhaps more importantly, coping with intrusive thoughts is also a serious challenge for people suffering 
from many mental disorders (Najmi \& Wegner, 2008; Purdon, 1999). In sum, knowing if or when thought suppression is effective would be of great use.

This article overviews thought suppression research methods. First, I discuss the so-called "white bear" paradigm. Experiments in this paradigm usually suggest that thought suppression is counterproductive. I describe the paradigm procedure and the theory which explains the results of the experiments. I also consider the paradigm's external and internal validity. Then, in a similar way, I describe the think/no-think paradigm. Research conducted in that paradigm generally indicates that thought suppression can be successful. I close with a brief discussion of alternative methods used to study thought suppression.

\section{The "white bear" paradigm}

The most famous experiments on thought suppression are those conducted in the so-called "white bear" paradigm. The inspiration for the paradigm came from Dostoyevsky's essay, in which he notices that when someone is asked not to think of a white bear, they will paradoxically think of it more intensively (Wegner, 1992). Roughly speaking, that is what was found in the first "white bear" study.

In this experiment, Wegner, Schneider, Carter and White (1987) divided participants into two groups. There were two five-minute experimental periods. The initial suppression group was instructed to avoid thoughts about a white bear for the first five minutes (the suppression period) and then to concentrate on it for the next five minutes (the expression period). Participants in the initial expression group were given the same instructions but in reverse order - they started by concentrating on a white bear and then tried to suppress white bear thoughts. In both periods, each participant verbalized their stream of consciousness and rang a bell when the thought of a white bear appeared.

The authors compared the frequency of critical thoughts in both groups. It turned out that participants from the initial suppression group had more thoughts of a white bear in the expression period than participants from the initial expression group. In other words, the thoughts the participants had tried to block appeared more frequently in the expression period than those preceded by no suppression attempts. This result is known as the rebound effect and it indicates that thought suppression has paradoxical consequences. The rebound effect has been replicated in many subsequent experiments in the "white bear" paradigm (for reviews see Abramowitz, 
Tolin \& Street (2001), Rassin, (2005), Wegner 2009 and Wenzlaff \& Wegner (2000)).

Wegner proposed the ironic mental control processes theory (1994) to explain why thought suppression backfires. The theory asserts that there are two processes involved in thought suppression: the operating process and the monitoring process. The former searches for mental contents that are not the unwanted ones and fills the mind with them. For example, when someone does not want to think about a white bear, the operating process would search for a substitute topic, such as the close environment, and make the person concentrate on it. If it succeeds, the operating process ends its work, unless there is a signal from the monitoring process. The monitoring process reviews potentially conscious material to determine the risk that the person is going to think an unwanted thought. If an unwanted thought is found, the operating process is reinitiated. Importantly, a search for unwanted mental content results in sensitivity to that content.

The operating process is controlled and requires many cognitive resources, while the monitoring process is automatic and less effortful. Given enough mental capacity, it may be possible not to think about something. Ironic effects appear when mental capacity is reduced. In such cases, the operating process cannot work properly, whilst the monitoring process works normally. The searching for an unwanted item and the attendant sensitivity to that item could cause the item to enter consciousness. The monitoring process is not sufficiently counterbalanced by the operating process and paradoxical effects are observed.

\section{Internal and external validity of the "white bear" paradigm}

The ironic mental control process theory enjoys substantial empirical support (e.g., Wegner, Broome \& Blumberg, 1997; Wegner \& Erber, 1992; Wegner, Erber and Zanakos, 1993; for review see Wegner, 2009). However, it does not explain the results of the experiments in other thought suppression paradigms (see below).

The "white bear" paradigm has its advantages and disadvantages. The fact that it involves suppressing a single item is one of the method's strong points, because it speaks to its ecological validity. Plausibly, people in real life tend to avoid thoughts concerning a particular topic, such as a painful break-up. Yet unwanted thoughts are usually emotionally charged, in contrast to thoughts about white bears. To address this problem, experiments have been conducted in the "white bear" paradigm that required partici- 
pants to suppress emotionally-charged mental contents (e.g., Koster, Rassin, Crombez \& Naring, 2003; Roemer \& Borkovec, 1994; Wegner \& Gold, 1995).

Another advantage of the "white bear" paradigm is that it enables us to determine whether the unwanted thoughts really appear in a person's consciousness by simply asking them about it. Researchers use other methods as well to evaluate mental item activation and make assessments concerning the frequency of certain thoughts. However, increased activation of a mental item can, but need not lead to thinking about that item.

Asking a person to reveal their stream of consciousness involves another risk. People can be reluctant to express their thoughts or even signal the thoughts' occurrence. They may not want an experimenter to know their thoughts or to discover the problems they have with controlling their minds. Alternatively, they may want to fulfil the researcher's presumed expectations and behave accordingly. Hence, such a self-report method is prone to individual attitudes and dispositions.

The monitoring and signaling of thoughts required by the "white bear" experimental procedure are not ecologically valid and can disturb the thought suppression process. The demand to remember an instruction such as "Ring the bell whenever you think of a white bear" also implies remembering the item to be suppressed. Moreover, signaling the occurrence of each critical thought increases the time devoted to the thought, which may increase the activation of the corresponding mental content. Additionally, observing one's thoughts from a meta-perspective is probably associated with consuming some mental resources that are stipulated to be required for the operating process to function properly. Furthermore, sometimes people may not be meta-aware of the fact that they are thinking about the item they should be avoiding (Baird, Smallwood, Fishman, Mrazek \& Schooler, 2013). Finally, because of the monitoring and signaling of the thoughts, the suppressed item may be processed more deeply, which can make it more difficult for the participant to forget it. A participant may pay more attention to her ability to control thoughts and be more anxious when the critical thought appears. Participants can also be afraid of an experimenter's unfavorable opinion of their mental control abilities. In such a case, an initially neutral thought can acquire a more personal meaning.

\section{The think/no-think paradigm}

The think/no-think paradigm serves as another method to study the effectiveness of thought suppression. It differs in many ways from the "white 
bear" paradigm but the most crucial difference concerns the results obtained in experiments conducted in the paradigms. More specifically, experiments in think/no-think paradigm indicate that thought suppression is usually successful.

The paradigm's procedure consists of three phases (Anderson \& Green, 2001; Levy \& Anderson, 2008). In the first one - the learning phase - participants memorize pairs of weakly associated words. Then, in the think/nothink phase, the first words of the memorized pairs (the cue-words) are presented. In most cases, if a participant sees a cue-word, they have to recall and say aloud the second word from the pair. However, sometimes the opposite instruction appears: the participant is to react to the cue-word by suppressing a thought about the associated word. It is important to note that some of the cue-words from the learning phase are not presented at all in the second phase. The words associated with them are the baseline words. The experiment ends with a memory test of all the second words from the pairs learned at the beginning.

If thought suppression is effective, the words suppressed in the "nothink" trials will be remembered worse than the words from the "think" trials and the baseline words. This means that the recall rate of the suppressed words should be lower than the recall rate of the words that were reminded less often during the experiment. Indeed, that was the general results pattern obtained from about seven hundred people taking part in the think/no-think experiments. Better memory for baseline words than for "no-think" words is called the negative control effect. The effect persisted even when the subjects had been paid to recall every word. The greater the number of presentations of a given cue-word in the think/no-think phase was given, the stronger the effect was. Moreover, there were no negative control effects when participants were asked just to restrain themselves from saying aloud the associated words without suppressing them (Anderson \& Green, 2001). Also, experiments using fMRI revealed that during the "nothink" trials the activity of the hippocampus (the brain structure selectively supporting episodic memories recolletion, Eldridge, Knowlton, Furmanski, Bookheimer \& Engel, 2000) was weakened compared with the "think" trials (Anderson et al., 2004) and was even lower than its activity while watching a fixation cross (Depue, Curran \& Banich, 2007). All of these results suggest that thought suppression can be effective.

Levy and Anderson (2008) proposed the so-called executive deficit hypothesis to explain the successes and failures in controlling thoughts. According to this account, thought suppression occurs through inhibition mechanisms. Thought control is analogous to behaviour control. People are 
able to restrain themselves from prepotent, but unwanted reactions. For example, they can stop the reflex to catch a falling object when the object is a prickly cactus (Anderson, 2006). Similarly, they can prevent a prepotent thought from entering consciousness if it is annoying or unpleasant. In the think/no-think paradigm, during the "no-think" trials, the cue-words remind participants of unwanted associated words. A person can inhibit them. The words are still inhibited after the phase. This is why participants do not remember them as well as baseline words.

The view that mechanisms underlying thought and behaviour control are congenial received support from neuroimaging experiments. Neural networks responsible for stopping motor responses overlap with neural networks involved in thought suppression (Anderson et al., 2004). The belowbaseline activity of the hippocampus during the "no-think" trials suggests that a memory is actually inhibited, not just replaced by another thought.

Researchers noticed that people vary in the ability to suppress thoughts (Levy \& Anderson, 2008). A meta-analysis showed that memory for "nothink" words was worse by an average of $6 \%$ than memory for baseline words. However, in some participants the magnitude of the negative control effect was $60 \%$, while in others the "no-think" words were remembered $40 \%$ better than baseline words. These disparities are derivative of individual differences in executive functions. The theory predicts that people having deficits in executive control will exhibit problems with thought suppression.

In line with that prediction, people who perform worse on tasks measuring complex working memory capacity (which probably measure executive control as well) have more difficulty suppressing thoughts than people with higher scores on this tasks. Moreover, there are populations that are claimed to have worse executive functioning, such as the elderly, children, and patients with damaged frontal lobes. The research shows that it is harder for members of these groups to forget selected material (for reviews see Levy \& Anderson (2008) and Anderson (2005); however, there are also results contrary to the hypothesis, e.g., Murray, Muscatell \& Kensinger, 2011).

\section{Internal and external validity of the think/no-think paradigm}

The executive deficits hypothesis explains when thought suppression is successful and when it is not. However, it does not account for the widely observed paradoxical effects of thought suppression. By contrast, Wegner's theory addresses this issue neatly but it fails to explain such phenomena as the negative control effect or the reduction in activity of the hippocampus. 
The strong point of the think/no-think paradigm is that it yields experimental results that are relatively unaffected by the participants' attitudes and motivations. As mentioned earlier, participants could not recall the suppressed words, even when paid. Participants in this paradigm do not expect the memory test so they cannot prepare for it.

In the think/no-think experiments there are no such confounding variables as the fear of being judged or additional mental resource consumption by metacognitive processes, which are present in "white bear" studies. Furthermore, keeping in mind the instruction "Do not think of the second word from the pair" does not necessarily entail keeping in mind the suppressed item (Levy \& Anderson, 2008).

In the absence of these confounding variables, however, the paradigm's external validity is relatively low. The experiment procedure is intended to resemble situations in which people encounter things that remind them of something they do not want to think about. Although there are similarities, the circumstances created in think/no-think experiments are generally artificial and do not appear outside the laboratory. There are many words to suppress and they are unconnected. As mentioned earlier, people tend to avoid thinking about a single mental content or a complex of closely-related contents. Moreover, avoided thoughts are usually well remembered and, at least before efforts to suppress them, easily come to mind. In the think/no-think paradigm, the associations are recent and their memory is not so strong.

\section{Other thought suppression research methods}

There are numerous alternative ways to study thought suppression. The list method of the directed forgetting paradigm is one of them (Sheard \& MacLeod, 2005). It is used to carry out research on selective and motivated forgetting which is fairly similar to blocking selected thoughts from consciousness. Experiments in this paradigm consist of two main phases. In the first phase, participants learn a list of words. Then an experimental group is asked to forget the words just memorized and to learn a second list of words instead. At the same time, the control group learns the second list without the "Forget the first list" instruction. In the second phase, the participants are tested to see how well they can remember words from the two lists. Usually, subjects from the experimental group are better at recalling words from the remember-list than from the forget-list. Memory for the remember-list is also better in that group than in the control group. 
Specific methods have also been developed to study particular aspects of thought suppression efficacy. For instance, in the study on suppression of stereotypic thoughts, researchers measured the distance that participants kept from the place occupied by a member of a subculture, wherein the bigger distance was believed to indicate the higher activation of the thoughts (Macrae, Bodenhausen, Milne \& Jetten, 1994). In turn, authors of the study on suppression thoughts about food used a computer game whose outcome determined the amount of chocolate bars participants received at the end of the experiment. Higher score in the game meant greater activation of thoughts about food (Johnston, Bulik \& Anstiss, 1999). Methods traditionally used to measure mental content activation are naturally also used in thought suppression studies. These include the lexical decision task (e.g., Giuliano \& Wicha, 2010), the scrambled sentences task (e.g., Wenzlaff $\&$ Bates, 1998), giving associations under time pressure, and the Stroop task (e.g., Wegner \& Erber, 1992).

The Stroop task was used among others in an important study by Wegner and Erber (1992). This research gave the first impulse for creating the ironic processes of mental control theory. In the study, the subjects suppressed or concentrated on words under high or low cognitive load while performing the Stroop task. Only the suppression under high cognitive load group displayed the interference effect during the exposition of avoided words. This result is interpreted as suggesting the hyperaccessibility of suppressed thoughts when mental resources are lacking.

There is one important issue that should be taken into consideration when analyzing the validity of these and other thought suppression research methods. In the light of Racsmány and Conway's article (2006), it is important which kind of memory is involved in the measurement of a mental item's activation. The authors hypothesize that the same representation can be processed in different and independent ways according to the type of cognitive structure by which the representation is accessed. Only the episodic memory stores a representation's activation/inhibition patterns. Hence, if a representation is accessed by another kind of knowledge structure, for example by the lexical one, the representation's activation will not be increased or decreased, regardless of whether the thoughts of it have been suppressed or not. These claims are in line with the results the authors obtained. In two directed forgetting experiments participants from the experimental group successfully forgot the words from the first list; however, the lexical decision test did not show attenuated activation of the words. Experiments have also been conducted from the so-called retrieval induced forgetting paradigm which 
also confirm the authors' hypothesis. It seems probable that effects of thought suppression are observed only if we use methods involving episodic memory.

\section{Conclusions}

Research on thought suppression is no simple task. There are many serious questions concerning the experiments' internal and external validity. The "white bear" paradigm seems to have better external validity than the think/no-think paradigm, which in turn seems to fare better in terms of internal validy. Methodological differences affect the results: experiments in the "white bear" paradigm suggest that thought suppression is generally counterproductive, while the think/no-think experiments indicate that activation of mental items can be intentionally inhibited. Other methods may also be used to study thought suppression. Research suggests that the validity of the methods depends on the kind of knowledge structure they involve.

Research on thought suppression could find many applications. People often would rather avoid unpleasant or disturbing thoughts which may concern distressing memories, fears, inappropriate associations or thoughts about temptations, physical pain, stereotypes. The issue of thought suppression effectiveness is also vital when it comes to some mental disorders such as posttraumatic stress disorder, obsessive-compulsive disorder, depression etc. Moreover, knowledge of the mechanisms of thought suppression may be of great use when creating devices controlled by a person's thoughts. Hence, it is important to seek optimal research methods which would enable us to find out if thought suppression can be effective in real life situations and which factors may affect it.

\section{I T E R A T U R E}

Abramowitz, J. S., Tolin, D. F., \& Street, G. P. (2001). Paradoxical effects of thought suppression: A meta-analysis of controlled studies. Clinical Psychology Review, 21(5), 683-703.

Anderson, M. C. (2005). The role of inhibitory control in forgetting unwanted memories: A consideration of three methods. In N. Ohta, C.M. MacLeod, B. Uttl (Eds.), Dynamic cognitive processes (pp. 159-190). Tokyo: SpringereVerlag.

Anderson, M. C. (2006). Repression: A cognitive neuroscience approach. In M. Mancia (Ed.), Neuroscience and psychoanalysis (pp. 327-349). Milan: Springer. 
Anderson, M. C., \& Green, C. (2001). Suppressing unwanted memories by executive control. Nature, 410(6826), 366-369.

Anderson, M. C., Ochsner, K. N., Kuhl, B., Cooper, J., Robertson, E., Gabrieli, S. W., Glover, G. H., \& Gabrieli, J. D. (2004). Neural systems underlying the suppression of unwanted memories. Science, 303(5655), 232-235.

Baird, B., Smallwood, J., Fishman, D. J., Mrazek, M. D., \& Schooler, J. W. (2013). Unnoticed intrusions: Dissociations of meta-consciousness in thought suppression. Consciousness and Cognition, 22(3), 1003-1012.

Depue, B. E., Curran, T., \& Banich, M. T. (2007). Prefrontal regions orchestrate suppression of emotional memories via a two-phase process. Science, $317(5835), 215-219$.

Giuliano, R. J., \& Wicha, N. Y. (2010). Why the white bear is still there: Electrophysiological evidence for ironic semantic activation during thought suppression. Brain Research, 1316, 62-74.

Johnston, L., Bulik, C. M., \& Anstiss, V. (1999). Suppressing thoughts about chocolate. International Journal of Eating Disorders, 26(1), 21-27.

Koster, E. H., Rassin, E., Crombez, G., \& Näring, G. W. (2003). The paradoxical effects of suppressing anxious thoughts during imminent threat. Behaviour Research and Therapy, 41(9), 1113-1120.

Levy, B. J., \& Anderson, M. C. (2008). Individual differences in the suppression of unwanted memories: the executive deficit hypothesis. Acta Psychologica, $127(3), 623-635$.

Macrae, C. N., Bodenhausen, G. V., Milne, A. B., \& Jetten, J. (1994). Out of mind but back in sight: Stereotypes on the rebound. Journal of Personality and Social Psychology, 67(5), 808-817.

Murray, B. D., Muscatell, K. A., \& Kensinger, E. A. (2011). Effects of emotion and age on performance during a think/no-think memory task. Psychology and Aging, 26(4), 940-955.

Najmi, S., \& Wegner, D. M. (2008). Mental control: Thought suppression and psychopathology. In A. Elliot (Ed.), Handbook of approach and avoidance motivation (pp. 447-459). Mahwah, NJ: Erlbaum.

Purdon, C. (1999). Thought suppression and psychopathology. Behaviour Research and Therapy, 37(11), 1029-1054.

Rachman, S., \& de Silva, P. (1978). Abnormal and normal obsessions. Behaviour Research and Therapy, 16(4), 233-248.

Racsmány, M., \& Conway, M. A. (2006). Episodic inhibition. Journal of Experimental Psychology: Learning, Memory, and Cognition, 32(1), 44-57.

Rassin, E. (2005). Thought suppression. Elsevier.

Roemer, L., \& Borkovec, T. D. (1994). Effects of suppressing thoughts about emotional material. Journal of Abnormal Psychology, 103(3), 467-474. 
Sheard, E. D., \& MacLeod, C. M. (2005). List method directed forgetting: Return of the selective rehearsal account. In N. Ohta, C. M. MacLeod, \& B. Uttl (Eds.), Dynamic cognitive processes (pp. 219-248). Tokyo: Springer-Verlag.

Wegner, D. M. (1992). You can't always think what you want: Problems in the suppression of unwanted thoughts. Advances in Experimental Social Psychology, 25, 193-225.

Wegner, D. M. (1994). Ironic processes of mental control. Psychological Review, 101(1), 34-52.

Wegner, D. M. (2009). How to think, say, or do precisely the worst thing for any occasion. Science, 325(5936), 48-50.

Wegner, D. M., Broome, A., \& Blumberg, S. J. (1997). Ironic effects of trying to relax under stress. Behaviour Research and Therapy, 35(1), 11-21.

Wegner, D. M., \& Erber, R. (1992). The hyperaccessibility of suppressed thoughts. Journal of Personality and Social Psychology, 63(6), 903-912.

Wegner, D. M., \& Gold, D. B. (1995). Fanning old flames: emotional and cognitive effects of suppressing thoughts of a past relationship. Journal of Personality and Social Psychology, 68(5), 782-792.

Wegner, D. M., Erber, R., \& Zanakos, S. (1993). Ironic processes in the mental control of mood and mood-related thought. Journal of Personality and Social Psychology, 65(6), 1093-1104.

Wegner, D. M., Schneider, D. J., Carter, S. R., \& White, T. L. (1987). Paradoxical effects of thought suppression. Journal of Personality and Social Psychology, $53(1), 5-13$.

Wenzlaff, R. M., \& Bates, D. E. (1998). Unmasking a cognitive vulnerability to depression: how lapses in mental control reveal depressive thinking. Journal of Personality and Social Psychology, 75(6), 1559-1571.

Wenzlaff, R. M., \& Wegner, D. M. (2000). Thought suppression. Annual Review of Psychology, 51(1), 59-91. 